\title{
Effect of herbal extract Eurycoma longifolia (Physta ) on female reproductive hormones and bone biochemical markers: an ovariectomised rat model study
}

\author{
Sasikala M. Chinnappan ${ }^{1 *}$, Annie George ${ }^{1}$ (D), Godavarthi Ashok ${ }^{2,3}$ and Yogendra Kumar Choudhary ${ }^{2}$
}

\begin{abstract}
Background: Each year 1.5 million women experience menopause when menstrual cycles cease resulting from the loss of ovarian function and oestrogen deprivation, a hormone that helps prevent bone loss. This study investigated the effects of Physta ${ }^{\oplus}$, a standardized herbal extract of Eurycoma longifolia Jack (PEL), on hormonal balance and parameters associated with hormonal imbalance, namely body and uterus weight and bone biochemical markers relevant in menopausal symptoms.
\end{abstract}

Methods: Forty-eight Sprague Dawley rats were randomly divided into six groups of eight rats each: (A) Sham operated; control (B) Untreated (ovariectomised (OVX) with vehicle), (C) PEL 100 (OVX + $100 \mathrm{mg} / \mathrm{kg}$ body weight (bw)), (D) PEL 300 (OVX + $300 \mathrm{mg} / \mathrm{kg}$ bw), (E) PEL 500 (OVX + $500 \mathrm{mg} / \mathrm{kg}$ bw) and (F) Positive control, testosterone undecanoate (TU) (OVX+10 mg/kg bw). Group A and B received daily oral administrations of the vehicle, Group C-E received daily oral administration of PEL and Group F received testosterone undecanoate intramuscularly weekly. At the end of 8 weeks, serum calcium, phosphate, bone alkaline phosphatase (BALP), osteocalcin, follicle stimulating hormone (FSH), luteinising hormone (LH), oestrogen, progesterone and testosterone were measured, then the animals were sacrificed and uterus was isolated, while weight was recorded in all experimental groups.

Results: Treatment of OVX rats with PEL at a dose of $500 \mathrm{mg} / \mathrm{kg}$ showed decreased serum FSH $(P<0.001,4.25 \pm$ $0.22 \mathrm{mlU} / \mathrm{ml})$ and $\mathrm{LH}(\mathrm{NS}, 4.07 \pm 0.12 \mathrm{mlU} / \mathrm{ml})$, while there was a significant increase in progesterone $(P<0.05$, $2.48 \pm 0.08 \mathrm{ng} / \mathrm{ml})$ and oestrogen $(P<0.05,11.02 \pm 0.13 \mathrm{pg} / \mathrm{ml})$ levels when compared to untreated group. PEL treatment at doses of $100 \mathrm{mg} / \mathrm{kg}, 300 \mathrm{mg} / \mathrm{kg}$ and $500 \mathrm{mg} / \mathrm{kg}$ showed a non-significant but increasing trend in serum calcium, phosphate, bone alkaline phosphate and testosterone levels. Ovariectomy resulted in a significant reduction $(P<0.001,238.81 \pm 5.39 \mathrm{mg})$ in uterus weight in the ovariectomised rats, which was alleviated in all PEL treated ovariectomised rats with an increasing trend of uterine weight.

Conclusion: The results suggest that PEL could be protective and beneficial for the management of reproductive hormone and bone markers. Therefore, it could be used to address hormonal imbalances and symptoms associated with menopause.

Keywords: Eurycoma longifolia, Ovariectomy, Hormonal balance

\footnotetext{
* Correspondence: sasikala.c@biotropicsmalaysia.com

${ }^{1}$ Biotropics Malaysia Berhad, Lot 21 Jalan U1/19, Section U1Hicom Glenmarie

Industrial Park, Shah Alam, Selangor, Malaysia

Full list of author information is available at the end of the article
}

(c) The Author(s). 2020 Open Access This article is distributed under the terms of the Creative Commons Attribution 4.0 International License (http://creativecommons.org/licenses/by/4.0/), which permits unrestricted use, distribution, and reproduction in any medium, provided you give appropriate credit to the original author(s) and the source, provide a link to the Creative Commons license, and indicate if changes were made. The Creative Commons Public Domain Dedication waiver (http://creativecommons.org/publicdomain/zero/1.0/) applies to the data made available in this article, unless otherwise stated. 


\section{Background}

Owing to the increased human life expectancy that has resulted from socioeconomic advancements and developments in medical technology, the post-menopausal period now accounts for over one-third of a woman's lifespan [1]. Menopause is a biological stage in a woman's life when menstrual cycles cease resulting from the loss of ovarian function and oestrogen deprivation, a hormone that helps prevent bone loss [2, 3]. Women in menopausal transition experience a variety of symptoms such as hot flashes, sweating, anxiety, depression, mood swings, sleep disorders, vaginal dryness and joint pain; all of which are due to the cessation of ovarian oestrogen production [4]. Bone loss also occurs in premenopausal women following ovariectomy (OVX) or treatment with gonadotrophin-releasing hormone agonists $[5,6]$. The rapid decline in endogenous oestrogen production that occurs during menopause results in a significant increase in bone turnover, thereby significant bone loss and increased risk for fragility fracture [7]. Ovariectomy is one of the most common surgical operations in women throughout the world, and is associated with an increased rate in bone resorption outweighing the increased rate of bone formation. Consequently, this leads to osteoporosis [8]. Ovarian hormone deficiency is the most important risk factor for post-menopausal osteoporosis $[9,10]$. Osteoblasts are cell that synthesise bone, whereas osteoclasts are bone cells that breakdown bone tissue. Stimulation of osteoblast differentiation has been suggested to be an important therapeutic approach for the prevention and treatment of osteoporosis [11].

Bone formation markers (BFM) are by-products of active osteoblasts expressed during different phases of their development and are considered to reflect different aspects of osteoblast function and bone formation [12]. The most widely used BFM are BALP, osteocalcin and the propeptides of type 1 collagen: these markers are measured in serum or plasma [12].

The use of ovariectomy, removal of both ovaries, as a model of oestrogen deficiency-induced hormonal imbalance and bone loss is widespread throughout discovery and pre-clinical translational research $[13,14]$. Typically, in this surgical model, bilateral removal of the ovaries occurs in young reproductively competent healthy animals. Experimental interventions occur either at the time of ovariectomy or commence once $17 \beta$-estradiol has reached a low to non-detectable level in plasma, which typically occurs within 1-2 weeks [15]. As a discovery strategy, data derived from the ovariectomy animal model has furthered the fundamental understanding of ovarian hormone action in every organ in the body [16].

In women, androgen production takes place in ovary, adrenal and peripheral tissues. Testosterone converted to oestrogen via aromatase activity in the peripheral compartments. Serum testosterone is an important marker of ovarian androgen production [17]. Based on past research other than oestrogen, hormones as progestins, testosterone, dehydroepiandrosterone (DHEA) were used as therapies for managing menopause related symptoms [18]. Testosterone replacement therapy was used in menopausal women to improve sexual desire, although it may have favourable effects on bones, muscles and cognitive function [19].

Eurycoma longifolia Jack (ELJ) is a small Asian tree belonging to the genus Eurycoma, commonly called as Tongkat Ali and Long Jack. The roots of ELJ are often called "Malaysian ginseng" [20] and is used for their antimalaria, anti-cancer and anti-ulcer properties. It has also been commonly prescribed in traditional medicine as a febrifuge and a remedy for dysentery, glandular swelling and fever [21, 22]. ELJ has been reported to have antioxidative properties due to its high concentration of superoxide dismutase $[19,20]$. ELJ supplementations were able to prevent the increase in bone resorption rate after orchiectomy by suppressing the elevation of C-terminal telopeptide of type I collagen [23].The root of ELJ is traditionally used globally for male sexual dysfunction and as an aphrodisiac. The compounds of the roots of this plant are scientifically tested and reported to have aphrodisiac and testosterone enhancing effects in the rat [24] as well as humans [25].

Hormone replacement therapy (HRT) is the strategy currently used for preventing and treating the symptoms of post menopause and post-menopausal related osteoporosis [26]. Ironically, long term HRT has been associated with increased risk of undesired side effects including headache, fluid retention, swollen breasts, breast cancer, endometrial cancer, venous thromboembolism, and cardiovascular disease [26, 27]. Consequently, there are no treatments that can be used safely in the long term in the management of post-menopausal syndromes, thus, it is necessary to develop a new drug of natural or synthetic origin, with minimal side effects [28].

The objective of the study was to evaluate if PEL is effective in maintaining hormonal balance and bone loss and to determine whether it is due to PEL's ability to increase testosterone levels as testosterone has been used to manage menopausal symptoms. One of the treatment groups in the study received testosterone undecanoate $10 \mathrm{mg} / \mathrm{kg}$ every 4 weeks $[19,29]$ as a source of testosterone and this group served as positive control group. The no observed adverse effect level (NOAEL) of ELJ water extract (Physta ${ }^{\oplus}$ ) was concluded as more than $1000 \mathrm{mg} / \mathrm{kg}$ orally based on acute, sub acute and 90 days sub-chronic studies [30]. As there was no study or any preliminary work available for ELJ on female reproductive hormone, a low $100 \mathrm{mg} / \mathrm{kg}$, medium $300 \mathrm{mg} / \mathrm{kg}$ and high $500 \mathrm{mg} / \mathrm{kg}$ doses which well below the NOAEL were used in the study. In the present study, serum calcium, phosphate, bone alkaline phosphatase, ostoecalcin, follicle stimulating hormone 
(FSH), luteinizing hormone (LH), progesterone, testosterone, oestrogen levels and uterus body weight of OVX rats treated with PEL were evaluated to elucidate the promising effects in management of menopausal related symptoms.

\section{Methods}

\section{Collection and preparation of plant extract}

ELJ extract used in the study was commercially available from Biotropics Malaysia under the trade name of Physta, PEL extract from batch number TA 170750 was used in this study. It is a water extract of the roots of ELJ, standardised based on Malaysian Standard for ELJ water extract MS 24089:2011 [31], with specification of 0.8-1.5\% eurycomanone, not less than $22 \%$ of total protein, not less than $30.0 \%$ of total polysaccharide and not less than $40.0 \%$ of glycosaponin. The HPLC fingerprint of PEL water extract was obtained according to the HPLC method using Kinetex $2.6 \mu \mathrm{m}$ EVO C18 $100 \AA(150 \times 4.6 \mathrm{~mm})$ column. The mobile phase consisted of solvent A- $0.02 \%$ trifluoroacetic acid in water and B - acetonitrile. A low gradient program with flow rate of $0.6 \mathrm{ml} / \mathrm{min}$ was set to $\mathrm{t}=0 \mathrm{~min} 5 \% \mathrm{~B} ; \mathrm{t}=9 \mathrm{~min}$ $7 \% \mathrm{~B} ; \mathrm{t}=12 \min 7.4 \% \mathrm{~B} ; \mathrm{t}=15 \mathrm{~min} 8 \% \mathrm{~B}$ followed by isocratic of $12 \% \mathrm{~B}$ between $\mathrm{t}=17-23 \mathrm{~min}$ and $18 \% \mathrm{~B}$ from $\mathrm{t}=$ 24-28 min. A gradual gradient was followed from $t=30$ $\min 20 \% \mathrm{~B} ; \mathrm{t}=35 \min 30 \% \mathrm{~B}, \mathrm{t}=40 \mathrm{~min} 35 \% \mathrm{~B}$ before final $\mathrm{t}=45-47 \mathrm{~min}$ at $95 \% \mathrm{~B}$. The major peak in chromatogram was compared against Eurycomanone standard (Fig. 1).

\section{Experimental animals}

The experimental protocol was approved by the Institutional Animal Ethics Committee (IAEC), proposal no. RR/IAEC/46-2017. The test facility, Radiant Research Services Pvt. Ltd. has been registered with Committee for the Purpose of Control and Supervision of Experiments on Animals (CPCSEA), New Dehli for in-house breeding and experimentation purpose. Forty-eight female inhouse breed of 12-week old Sprague Dawley rats weighing $120-250 \mathrm{~g}$ were acclimatised in polypropylene cages with stainless steel top grill in standard laboratory conditions of $22 \pm 3{ }^{\circ} \mathrm{C}, 30-70 \%$ relative humidity and a $12 \mathrm{~h}$ light-dark cycle. They were maintained under standard






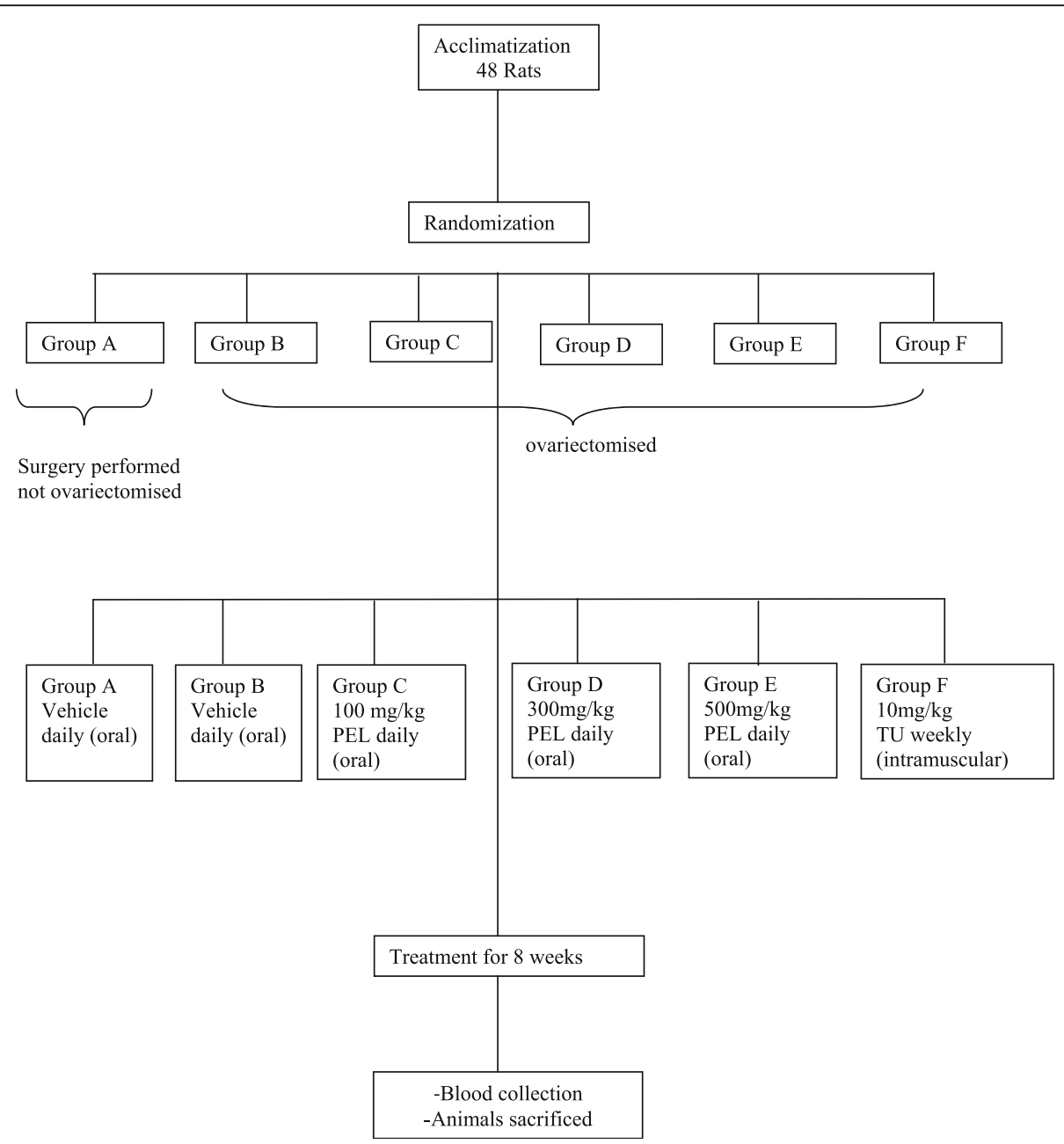

Fig. 2 Randomization and Treatment Schedule Flow Chart

housing conditions with free excess to a standard diet (M/s. Amruth labs, Bangalore, India) and water ad libitum during the study. During acclimatization period 5 rats were housed in a single cage according to CPCSEA guideline and during dosing period (after surgical) single rat was placed in a cage. Sterile paddy husk was used as bedding material and changed at least twice a week.

The animals were randomly divided into six experimental groups (Fig. 2), with each group consisting of eight rats. All animals were uniquely marked with picric acid and recorded. Group A: Sham operated control group (rats were operated on but the ovaries were not removed), received vehicle ( $0.5 \%$ carboxy methyl cellulose sodium) for 8 weeks; Group B: Untreated group (surgery was performed and ovaries were removed), received vehicle for 8 weeks; Group C: Low dose group, ovariectomised animals received daily oral treatment of PEL $100 \mathrm{mg} / \mathrm{kg}$ body weight for 8 weeks; Group D: Mid dose group, ovariectomised animals received daily oral treatment of PEL $300 \mathrm{mg} / \mathrm{kg}$ body weight for 8 weeks;
Group E: High dose group, ovariectomised animals received daily oral treatment of PEL $500 \mathrm{mg} / \mathrm{kg}$ body weight for 8 weeks; Group F: Positive control group, ovariectomised animals receiving testosterone undecanoate (TU) (Sun Pharma Laboratories Ltd) $10 \mathrm{mg} / \mathrm{kg}$ body weight intramuscularly once in every weeks for 8 weeks. During the experimental period the animals were dosed during 10 to 11 a.m. Animals were dosed at the volume of $10 \mathrm{ml} / \mathrm{kg}$ based on most recent recorded body weight. Clinical signs, mortality and feed intake were determined daily, whereas body weight was recorded before surgery, weekly thereafter and at the end of the dosage schedule. All the procedures were carried out in procedure room.

At the end of the treatment period, the rats were fasted overnight, and $1.5 \mathrm{ml}$ blood was collected via a retro orbital route. The rats were anaesthetised with $5 \%$ isoflurane the commonly used inhalant aesthetic [32]. The serum samples were prepared by centrifugation ( $3000 \mathrm{rpm}$ for 10 mins) of the collected blood samples and then stored at $80^{\circ} \mathrm{C}$ for biochemical determinations. Animals were then 
sacrificed using 5\% extended isoflurane anaesthesia (Raman \& Well Pvt. Ltd) through inhalation the uterus was dissected out, adhering fat was removed, washed with saline solution and immediately weighed. After removing uterus those animals which gets recovered from the extended isoflurane anaesthesia was euthanized by $\mathrm{CO}_{2}$ inhalation method at a flow rate of $5 \mathrm{~L} / \mathrm{min}\left(\mathrm{CO}_{2}\right.$ flow was maintained for at least $1 \mathrm{~min}$ after respiratory arrest).

\section{Surgical procedure}

Anaesthesia was induced by intraperitoneal injection of ketamine $\mathrm{HCl}(80 \mathrm{mg} / \mathrm{kg}$ ) (Neon Laboratories Ltd) as it has less effect on the rate and blood pressure. The depth of anaesthesia was checked by monitoring the respiratory rate or simply testing the animal response to gentle pressure on the hind paws. After the onset of anaesthesia, clippers were used to clip the skin and fur shaved bilaterally to expose the skin. The procedure was conducted by making two incisions to separately reach each ovary. The shaved skin was swab with 70\% (v/v) ethanol and the anaesthetised animal was placed on the operating table with its back exposed and its tail towards the operator. A single dorsal incision $(1 \mathrm{~cm})$ was made penetrating the skin using small scissors in the lower back, directly below the bottom of the rib cage. Gently subcutaneous connective tissue was made freed from the underlying muscle on each side using blunt forceps. The ovary was located under the thin muscle layer and a small incision (less than $1 \mathrm{~cm}$ ) was made on each side to gain entry to the peritoneal cavity. The edge of the incision was held securely with tooth forceps and the ovarian fat pad was retracted surrounding ovaries with blunt forceps to expose the oviduct. The ovary was removed by gently severing the oviduct, using sterile, small scissors. The uterus and remaining part of the oviduct was replaced back into the abdominal cavity. The muscle layer was sutured and the procedure was repeated for the other ovary. A suitable analgesic meloxicam (Intas Pharmaceuticals Ltd) was administered subcutaneously at a dose of $5 \mathrm{mg} / \mathrm{kg}$ body weight post operatively [32].

\section{Biochemical analysis}

Serum concentrations of calcium, phosphate, bone alkaline phosphatase, ostoecalcin, $\mathrm{FSH}, \mathrm{LH}$, progesterone, testosterone and oestrogen were measured using commercial assay kits. Calcium and phosphate levels were measured using a fully Automated Clinical Chemistry Analyzer EM360, Transasia Bio-medicals Ltd. Calcium was analysed by an ERBA calcium kit (Lot No: B071648) by the method of aresenazo III. Phosphate was analysed using the ERBA Phosphate kit (Lot No: B071630) by an ammonium molybdate method using a biochemistry EM 360 analyser. Bone type of alkaline phosphatase was assayed using an Elabsciences ELISA kit (Cat No.: E-EL-R1109).
Osteocalcin was tested using Elabsciences ELISA kit (Cat No.: E-EL-R0243). FSH was analysed using a Roche Follicle Stimulating Hormone kit (Lot No: 033208), LH was analysed using a Roche Luteinising Hormone kit (Lot No: 030208). Oestrogen was analysed using a Roche Estradiol kit (Lot No: 127038), Progesterone was analysed by a Roche progesterone kit (Lot No: 0278) and testosterone was tested using a Roche Testosterone kit (Lot No: 180003). All these reproductive hormone estimations were performed by the method of C4SA (CLIA Chemiluminescence immunoassay) using a Siemens fully auto analyser (Model No. EXL-200) according to the manufacturer's protocol.

\section{Statistical analysis}

All data including body weight, feed consumption, biochemical evaluation and organ weights were statistically analysed using Graph-Pad Prism Software, version 5.01. All values were expressed as mean \pm SEM. The significant difference between the treatment and control group was estimated using one-way ANOVA with Tukey's post test and the results were considered statistically significant at $P<0.05$.

\section{Results}

\section{Effect on body weight of rat}

The rats in all experimental groups had similar initial body weights, but 8 weeks after surgery, the untreated rats showed a significant increase in body weight gain (41.22 $\left.\pm 2.85 \%,{ }^{\# \#} P<0.01\right)$ compared to the control group. Treatment with PEL $500 \mathrm{mg} / \mathrm{kg}$ prevented the ovariectomy-induced weight gain $(36.00 \pm 1.44 \%)$ when compared to the untreated group $(41.22 \pm 2.85 \%)$ at week 8 , with the sham control group showing the lowest percentage weight gain $(29.86 \pm 1.98 \%)$ at week 8 . The increase in body weight from the start of the study to 8 weeks was inhibited in PEL treated groups in a dose dependent manner. No significant changes were observed in the percentage weight gain in all treatment groups when compared to the untreated group during the study period (Table 1).

Table 1 Effect of PEL on percentage (\%) rat body weight gain

\begin{tabular}{llll}
\hline Groups & \multicolumn{2}{l}{ Weight (g) } & $\begin{array}{l}\text { Percentage } \\
\text { Weight Gain } \\
\text { (\%) Week 8 }\end{array}$ \\
\cline { 2 - 3 } & Basal & Week 8 & $29.86 \pm 1.98$ \\
\hline Group A Sham control & $186.8 \pm 9.60$ & $242.1 \pm 7.62$ & $21.22 \pm 2.85^{\# \#}$ \\
Group B Untreated & $185.1 \pm 5.45$ & $261.1 \pm 7.73$ & 41.25 .52 \\
Group C PEL 100 mg/kg & $185.4 \pm 5.32$ & $258.5 \pm 6.82$ & $39.59 \pm 1.66$ \\
Group D PEL 300 mg/kg & $185.4 \pm 6.28$ & $253.9 \pm 7.20$ & $37.41 \pm 3.31$ \\
Group E PEL 500 mg/kg & $185.8 \pm 6.23$ & $252.5 \pm 8.31$ & $36.00 \pm 1.44$ \\
Group F Positive control & $185.0 \pm 3.35$ & $259.3 \pm 4.85$ & $40.14 \pm 0.73$
\end{tabular}

Data stated as mean $\pm \mathrm{SEM} ;{ }^{\# \#} P<0.01$ vs. Group A 
Table 2 Effect of PEL on uterus weight

\begin{tabular}{llllll}
\hline UTERUS WEIGHT $(\mathrm{mg})$ & & & & \\
\hline Group A & Group B & Group C & Group D & Group E & Group F \\
\hline $679.06 \pm 6.65$ & $238.81 \pm 5.39^{\# \# \#}$ & $235.84 \pm 4.03$ & $240.73 \pm 2.93$ & $256.39 \pm 4.41$ & $389.74 \pm 8.26^{* * *}$ \\
\hline
\end{tabular}

Data stated as mean \pm SEM; ${ }^{\# \#} P<0.001$ vs. Group $A_{;}{ }^{* * *} P<0.001$ vs. Group B

\section{Effect on organ weight}

Ovariectomy resulted in a significant reduction $(P<0.001$, $238.81 \pm 5.39 \mathrm{mg})$ in uterus weight in the ovariectomised rats and administration of PEL and testosterone undecanoate after ovariectomy inhibited further loss of uterus weight. The administration of testosterone showed a significant increase $(P<0.001,389.74 \pm 8.26 \mathrm{mg})$ in uterine weight compared to the untreated group. An increasing dose-dependent trend was observed in PEL treatment groups (Table 2).

\section{Effect on serum biochemistry}

The effects of PEL on serum biochemical markers are summarised in Tables 3 and 4. Untreated rats showed a significant decrease in calcium $(P<0.001,7.86 \pm 0.12 \mathrm{mg} / \mathrm{dl})$, phosphate $(P<0.001,2.83 \pm 0.12 \mathrm{mg} / \mathrm{dl})$ and bone specific alkaline phosphatase (BALP) $(P<0.001,2.54 \pm 0.20 \mathrm{ng} / \mathrm{ml})$ compared to the sham control group. However, in the positive control group animals treated with testosterone undecanoate, there was a significant increase in calcium $(P<0.05,8.48 \pm 0.16 \mathrm{mg} / \mathrm{dl})$, phosphate $(P<0.05,3.29 \pm$ $0.13 \mathrm{mg} / \mathrm{dl})$ and BALP $(P<0.05,3.06 \pm 0.12 \mathrm{ng} / \mathrm{ml})$ levels compared to the untreated group. Similarly, treatment with PEL increased the serum calcium, phosphate and BALP levels in a dose dependent manner compared to the untreated group. There were no significant changes observed in the ostoecalcin levels in all the treated groups compared to the untreated group. Ovariectomy appears to significantly increase serum FSH $(P<0.001,5.70 \pm 0.33 \mathrm{mIU} / \mathrm{ml})$ and LH $(P<0.001,4.69 \pm 0.22 \mathrm{mIU} / \mathrm{ml})$ levels in the untreated group compared to the sham control group. However, treatment of ovariectomised rats with TU significantly reduced the serum FSH $(P<0.001,3.96 \pm$ $0.22 \mathrm{mIU} / \mathrm{ml})$ and $\mathrm{LH}(P<0.001,3.76 \pm 0.11 \mathrm{mIU} / \mathrm{ml})$ levels compared to the untreated group. The effect of PEL $500 \mathrm{mg} / \mathrm{kg}$ on serum FSH was significant, where it was reduced compared to the untreated group $(P<0.001,4.25 \pm$
$0.22 \mathrm{mIU} / \mathrm{ml}$ ), but the decrease in the level of serum $\mathrm{LH}$ did not reach statistical significance. A significant drop in serum levels of progesterone, oestrogen and testosterone were observed in the untreated group compared to the sham control group, whereas there was a significant increase in the levels of progesterone $(P<0.001,3.31 \pm 0.15$ $\mathrm{ng} / \mathrm{ml})$, oestrogen $(P<0.001,12.35 \pm 0.25 \mathrm{pg} / \mathrm{ml})$ and testosterone $(P<0.001,13.01 \pm 0.41 \mathrm{ng} / \mathrm{ml})$ in the positive control group. As expected, progesterone $(P<0.05,2.48 \pm$ $0.08 \mathrm{ng} / \mathrm{ml})$, oestrogen $(P<0.05,11.02 \pm 0.13 \mathrm{pg} / \mathrm{ml})$ and testosterone (NS, $1.83 \pm 0.03 \mathrm{ng} / \mathrm{ml}$ ) levels were increased by treatment with PEL $500 \mathrm{mg} / \mathrm{kg}$ (Table 3).

\section{Discussion}

Ovariectomy is a standard surgical procedure to induce menopause in experimental animals and ovariectomised female rats show a dramatic cessation of ovarian function and higher risk of osteoporosis [33, 34]. The effect of ovariectomy was clearly seen in the untreated group where level of investigated hormones, serum bone biomarkers, body weight gain and uterus weight were significantly altered compared to the sham control group. The study findings show supplementation of PEL and testosterone alleviated the changes in all the parameters investigated in ovariectomised rats.

The weight gain in ovariectomised rats was significantly higher compared to the sham control group, which may be related to oestrogen insufficiency. The effect of oestrogen insufficiency on lipid metabolism during menopause has been well documented [34], and it is the main reason for an increase in adiposity, particularly abdominal fat accumulation [34]. Even though not significant, supplementation of PEL has ability to inhibit weight gain in a dose dependent manner.

The ovariectomised rats that did not undergo any treatment showed a significant decrease in uterine weight compared to those rats which only underwent a

Table 3 Effect of PEL on serum calcium, phosphate, BALP and osteocalcin levels

\begin{tabular}{lllll}
\hline Groups & Calcium $(\mathrm{mg} / \mathrm{dl})$ & Phosphate $(\mathrm{mg} / \mathrm{dl})$ & Bone Alkaline phosphatase $(\mathrm{ng} / \mathrm{ml})$ & Osteocalcin $(\mathrm{ng} / \mathrm{ml})$ \\
\hline Group A Sham control & $9.05 \pm 0.20$ & $3.71 \pm 0.14$ & $3.43 \pm 0.11$ & $7.13 \pm 0.34$ \\
Group B Untreated & $7.86 \pm 0.12^{\# \# \#}$ & $2.83 \pm 0.12^{\# \# \#}$ & $2.54 \pm 0.20^{\# \# \#}$ & $7.86 \pm 0.48$ \\
Group C $100 \mathrm{mg} / \mathrm{kg}$ & $7.85 \pm 0.12$ & $2.83 \pm 0.11$ & $2.57 \pm 0.04$ & $7.89 \pm 0.06$ \\
Group D $300 \mathrm{mg} / \mathrm{kg}$ & $7.98 \pm 0.11$ & $2.89 \pm 0.08$ & $2.70 \pm 0.11$ & $7.79 \pm 0.21$ \\
Group E 500 mg/kg & $8.11 \pm 0.11$ & $3.01 \pm 0.12$ & $2.82 \pm 0.10$ & $7.52 \pm 0.18$ \\
Group F Positive control & $8.48 \pm 0.16^{*}$ & $3.29 \pm 0.13^{*}$ & $3.06 \pm 0.12^{*}$ & $7.26 \pm 0.20$ \\
\hline
\end{tabular}

Data stated as mean $\pm \mathrm{SEM}$; ${ }^{\# \#} P<0.05$, ${ }^{\# \#} P<0.01$ and ${ }^{\# \# \#} P<0.001$ vs. Group $A ;{ }^{*} P<0.05,{ }^{* *} P<0.01$ and ${ }^{* * *} P<0.001$ vs. Group $B$ 
Table 4 Effect of PEL on serum FSH, LH, progesterone, oestrogen and testosterone levels

\begin{tabular}{llllll}
\hline Groups & FSH $(\mathrm{mlU} / \mathrm{ml})$ & $\mathrm{LH}(\mathrm{mlU} / \mathrm{ml})$ & Progesterone $(\mathrm{ng} / \mathrm{ml})$ & Oestrogen $(\mathrm{pg} / \mathrm{ml})$ & Testosterone $(\mathrm{ng} / \mathrm{ml})$ \\
\hline Group A Sham control & $2.26 \pm 0.07$ & $1.73 \pm 0.05$ & $5.78 \pm 0.25$ & $29.31 \pm 0.60$ & $4.48 \pm 0.21$ \\
Group B Untreated & $5.70 \pm 0.33^{\# \# \#}$ & $4.69 \pm 0.22^{\# \# \#}$ & $1.82 \pm 0.09^{\# \# \#}$ & $9.49 \pm 0.27^{\# \# \#}$ & $1.22 \pm 0.06^{\# \# \#}$ \\
Group C PEL $100 \mathrm{mg} / \mathrm{kg}$ & $5.29 \pm 0.27$ & $4.57 \pm 0.18$ & $1.88 \pm 0.05$ & $9.52 \pm 0.15$ & $1.21 \pm 0.04$ \\
Group D PEL $300 \mathrm{mg} / \mathrm{kg}$ & $4.87 \pm 0.20$ & $4.36 \pm 0.20$ & $1.96 \pm 0.09$ & $10.18 \pm 0.28$ & $1.31 \pm 0.03$ \\
Group E PEL 500 mg/kg & $4.25 \pm 0.22^{* * *}$ & $4.07 \pm 0.12$ & $2.48 \pm 0.08^{*}$ & $11.02 \pm 0.13^{*}$ & $1.83 \pm 0.03$ \\
Group F Positive control & $3.96 \pm 0.22^{* * *}$ & $3.76 \pm 0.11^{* *}$ & $3.31 \pm 0.15^{* * *}$ & $12.35 \pm 0.25^{* * *}$ & $13.01 \pm 0.41^{* * *}$ \\
\hline
\end{tabular}

Data stated as mean \pm SEM; ${ }^{\#} P<0.05,{ }^{\# \#} P<0.01$ and ${ }^{\# \# \#} P<0.001$ vs. Group $A ;{ }^{*} P<0.05,{ }^{* *} P<0.01$ and ${ }^{* * *} P<0.001$ vs. Group B

sham operation. The reduction of uterine weight was due to an atrophy of endometrium resulting from a lack of hormones secreted by the ovaries [34]. Oestrogen plays a predominant role in reducing uterine weight gain. The ovariectomy caused reduction in oestrogen hormone, thereby reducing uterine oestrogen receptors, leading to a decrease in the proliferative layers, luminal epithelium, thin stroma and myometrium, subsequently reducing uterus weight [35]. However, the administration of PEL to ovariectomised rats for 8 weeks appeared to reduce the weight loss, mainly by minimising uterine atrophy compared to the untreated ovariectomised rats. This improvement in uterine atrophy and weight is probably due to increases in the oestrogen levels in PEL supplemented groups.

The prevalence of osteoporosis increases with age, whereby bone loss (loss of calcium, phosphate and BALP) is reportedly more rapid in females in the first few years post menopause and is influenced by oestrogen deficiency [36]. In the present study, ovariectomy caused a significant loss of calcium and phosphate levels in untreated rats when compared to the sham control rats, similar to other published studies [37, 38]. This could be related with ovarian hormone deficiency inducing the synthesis of cytokines by osteoblasts, monocytes and $\mathrm{T}$ cells, thereby initiating bone resorption by increasing osteoclast activity [39]. The action cause reduced intestinal calcium absorption and may contribute towards a lower level of calcium in blood serum. A pre-clinical study on rats supports the positive effects of TA on bone turnover in androgendeficient rats [40], as TA supplementation reduced the percentage of osteoclasts and increased the percentage of osteoblasts on the bone surface [40]. The measurement of BALP activity can be used as a marker of bone formation and bone resorption in vivo $[34,41]$. Treatment with PEL has the potential to reduce bone loss in the OVX rats by elevating calcium, phosphate and BALP levels.

The onset of menopause is associated with a dramatic change in hormonal balance, a decrease in oestrogen and increase in FSH and LH hormones, which ultimately reduces the level of progesterone and causes permanent amenorrhea [42, 43]. Accordingly, serum FSH and LH levels were significantly increased in the untreated group compared to the sham control group, possibly due to the increased release of luteinising hormone releasing hormone which has been shown to cause higher serum FSH and LH levels in menopausal female rats [35]. These biomarkers were significantly decreased in OVX rats treated with PEL compared to the untreated rats. A significant depletion in the level of progesterone, oestrogen and testosterone in the untreated group provides evidence that the ovariectomy results in postmenopausal like symptoms. Administration of PEL at high dose to the OVX rats significantly increased the levels of progesterone and oestrogen, and there was a trend for increased testosterone level. This corroborates with a previous study in which ELJ increased testosterone levels in hypogonadic men [25], hence has the ability to trigger the production of testosterone from other organs such as adrenal cortex. There are few mechanisms to explain the increase in testosterone by ELJ supplementation. High performance liquid choromatography (HPLC) analysis of aqueous extract and fractions from various ratio of watermethanol extraction shows that ELJ contain four major quassinoids ie. eurycomanone, $13 \alpha(21)$-epoxyeurycomanone, 13,21-dihydroeurycomanone and eurycomanol [44]. The effect of these quassinoids on male fertility and testosterone production was investigated and found to increase testosterone levels in the testis and plasma of rats supplemented with eurycomanone fraction. The same study also concluded that the testosterone elevating effect of eurycomanone was dose dependant. As such it is possible that eurycomanone could be one of the bioactive markers of PEL.

Apart from eurycomanone ELJ is reported to contain peptide which enhance the biosynthesis of various androgens [45]. The peptide was shown to activate the CYP17 (17 $\alpha$-hyroxylase/17, 20 lyase) enzyme to enhance the metabolism of pregnenolone and 17-OH-pregnenolone to yield more dehyroepiandrosterone (DHEA). Progesterone and 17-OH-progesterone are further metabolised to 4androstenedione and testosterone [46]. As testosterone is the precursor hormone for oestrogen via aromatisation, the testosterone can be further aromatised to oestrogen. This explains the increase in the oestrogen levels in animals treated with PEL containing the bioactive peptide. 
Most menopausal symptoms are caused by fluctuating hormone levels. Supplementation of PEL can stabilise the fluctuation of hormone levels in the ovariectomised rats, indicating the potential of PEL to alleviate menopausal related symptoms. Future investigations will evaluate other parameters, such as bone mineral density, additional bone formation markers, bone resorption markers, histology of uterus and tibia bone to further understand how PEL can minimise changes in hormonal and bone related biomarkers in ovariectomised rats.

\section{Conclusion}

The present study, demonstrated that PEL could reduce bone loss and improve hormonal levels caused by ovariectomy, an animal model depicting menopause. Furthermore, the effects of PEL on reproductive hormones and bone markers were dose dependent. Hence, PEL may be considered for menopause management and clinically evaluated in future studies in this area.

\begin{abstract}
Abbreviations
ALP: Alkaline phosphatase; ANOVA: One-way analysis of variance; BALP: Bone specific alkaline phosphate (BALP); BFM: Bone formation markers; bw: Body weight; CLIA: Chemiluminescence immunoassay; CPCSEA: Committee for the Purpose of Control and Supervision of Experiments on Animals; CTx: Cterminal telopeptide of type I collagen; DHEA: Dehydroepiandrosterone; ELISA: Enzyme linked immune sorbent assay; ELISA: Enzyme linked immunoassay kit; ELJ: Eurycoma longifolia Jack; FSH: Follicle stimulating hormone; HCL: Hydrochloric acid; HRT: Hormone replacement therapy; IAEC: Institutional Animal Ethics Committee; LH: Luteinising hormone; LHRH: Luteinising hormone releasing hormone; OVX: Ovariectomy; PEL: Physta Eurycoma longifolia; TU: Testosterone undecanoate
\end{abstract}

\section{Acknowledgements}

The technical assistance of Vandana Choudhary, Yesha Ramani and Rashmi Dewangan of the ECPL, India, is gratefully acknowledged.

\section{Authors' contributions}

SMC, AG, GA and YKC designed all laboratory experiments. GA conducted all experiments and statistical analysis. SMC, AG, YKC interpreted the results, drafted and reviewed the manuscript. All authors read and approved the manuscript.

\section{Funding}

Biotropics Malaysia Berhad, Shah Alam, Selangor, Malaysia funded the study. SMC and AG are employees of the funders and involved in study design, results interpretation and manuscript drafting. All authors acknowledge the funding.

\section{Availability of data and materials}

The datasets used and/or analysed during the current study available from the corresponding author on reasonable request.

\section{Ethics approval and consent to participate}

This study was approved by the Institutional Animal Ethics Committee (IAEC), RR, India, proposal no. RR/IAEC/46-2017 dated 16.12.2017 and conformed to the guidelines of The Committee for the Purpose of Control and Supervision of Experiments on Animals (CPCSEA), MOEF, Government of India for studies involving experimental animals.

\section{Consent for publication}

Not applicable.

\section{Competing interests}

SMC and AG are employees of Biotropics Malaysia Berhad. The authors declare that there is no conflict of interests.

\section{Author details}

${ }^{1}$ Biotropics Malaysia Berhad, Lot 21 Jalan U1/19, Section U1Hicom Glenmarie Industrial Park, Shah Alam, Selangor, Malaysia. ${ }^{2}$ Etica Clinpharm Pvt. Ltd, Raipur, Chhattisgarh 492001, India. ${ }^{3}$ Radiant Research Services Pvt. Ltd, 99/A, 8 main, III Phase, Peenya Industrial Area, Bangalore 560058, India.

Received: 13 July 2019 Accepted: 9 January 2020

Published online: 05 February 2020

\section{References}

1. Choi MS, Park JW. A study of educational need, attitude and knowledge toward menopause in middle-aged women. Korean J Women Health Nurs. 2008;14:257-69.

2. Dalal PK, Agarwal M. Postmenopausal syndrome. Indian J Psychiatry. 2015; 57:222-32.

3. Nelson HD. Menopause. Lancet. 2008;371:760-70.

4. Doyle BJ, Frasor J, Bellows LE, et al. Estrogenic effects of herbal medicines from Costa Rica used for the management of menopausal symptoms. Menopause. 2009;16(4):748-55.

5. Hibler E, Kauderer J, Greene MH, Rodriguez GC, Alberts DS. Bone loss following oophorectomy among high-risk women: an NRG oncology/ gynecologic oncology group study. Menopause. 2016;23(11):1228.

6. Di Vasta AD, Feldman HA, Gallagher JS, Stokes NA, Laufer MR, Hornstein MD, Gordon CM. Hormonal add-back therapy for females treated with gonadotropin-releasing hormone agonist for endometriosis: a randomized controlled trial. Obstet Gynecol. 2015;126(3):617.

7. Golob AL, Laya MB. Osteoporosis: screening, prevention, and management. Med Clin North Am. 2015;99(3):587-606.

8. He C, Hui R, Tezuka Y, Kadota S, Li J. Osteoprotective effect of extract from Achyranthes bidentata in ovariectomized rats. J Ethnopharmacol. 2010; 127(2):229-34

9. Richelson LS, Wahner HW, Melton LJ, Riggs BL. Relative contributions of aging and estrogen deficiency to postmenopausal bone loss. N Engl J Med. 1984;311:1273-5.

10. Arjmandi BH, Johnson SA, Pourafshar SH, Navaei NH, George KS, Akhavan NS. Dried Plum's unique ability to prevent and reverse bone loss in ovarian hormone deficiency: efficacy and possible mechanisms. FASEB J. 2017;31:151-8.

11. Bark C. Normal bone anatomy and physiology. Clin J Am Soc Nephrol. 2008; 3:S131-9.

12. Shetty S, Kapoor N, Bondu JD, Thomas N, Paul TV. Bone turnover markers: emerging tool in the management of osteoporosis. Indian J Endocr Metab. 2016;20(6):846.

13. Van Kempen TA, Milner TA, Waters EM. Accelerated ovarian failure: a novel, chemically induced animal model of menopause. Brain Res. 2011;1379:176-87.

14. Brinton RD. Investigative models for determining hormone therapy-induced outcomes in brain: evidence in support of a healthy cell bias of estrogen action. Ann N Y Acad Sci. 2005;1052:57-74.

15. Brinton RD. Mini review: translational animal models of human menopause: challenges and emerging opportunities. Endocrinology. 2012;153(8):3571-8.

16. Faulds MH, Zhao C, Dahlman-Wright K, Gustafsson JÅ. The diversity of sex steroid action: regulation of metabolism by estrogen signaling. J Endocrinol. 2012;212:3-12.

17. Lobo RA. Androgens in postmenopausal women: production, possible role, and replacement options. Obstet Gynecol Surv. 2001;56(6):361-76.

18. Nelson HD, Haney EM, Humphrey L, Miller J, Nedrow A, Nicolaidis C, Nygren P. Management of menopause-related symptoms. Summary, evidence technology assessment no 120. (prepared by the Oregon evidence based practice center, under contract no 290-02-0024). AHRQ publication no 05E016-1. Rockville: Agency for healthcare research and quality; 2005.

19. Bonilla-Becerra SM, de Oliveira MG, Calmasini FB, Rojas-Moscoso JA, Zanesco $A$, Antunes E. Micturition dysfunction in four-month old ovariectomized rats: effects of testosterone replacement. Life Sci. 2017;179:120-9.

20. Talbott SM, Talbott JA, George A, et al. Effect of Tongkat Ali on stress hormones and psychological mood state in moderately stressed subjects. J Int Soc Sports Nutr. 2013;10:28.

21. Suh KS. Discovery of novel biomarkers for the development of personalized medicine. Transl Med. 2012;51:e1-2. 
22. Teh CH, Teoh SC, Yeap CS, Chan KL, Fun HK. 4, 5, 7, 8, 17-Pentahydroxy-14, 18-dimethyl-6-methylene-3, 10-dioxapentacyclo [9.8. 0.01, 7.04, 19.013, 18] nonadec-14-ene-9, 16-dione methanol solvate dehydrate. Acta Crystallogr Sect E: Struct Rep Online. 2009;65:898-9.

23. Shuid AN, Ping LL, Muhammad N, Mohamed N, Soelaiman IN. The effects of Labisia pumila var. alata on bone markers and bone calcium in a rat model of post-menopausal osteoporosis. J Ethnopharmacol. 2011;133(2):538-42.

24. Rehman S, Choe K, Yoo H. Review on a traditional herbal medicine, Eurycoma longifolia Jack (Tongkat Ali): its traditional uses, chemistry, evidence-based pharmacology and toxicology. Molecules. 2016;21(3):331.

25. Tambi MI, Imran, MK, Henkel RR. Standardised water-soluble extract of Eurycoma longifolia, Tongkat Ali, as testosterone booster for managing men with late-onset hypogonadism? Andrologia. 2010;44:1-5.

26. Davison S, Davis SR. Hormone replacement therapy: current controversies. Clin Endocrinol. 2003;58:249-61.

27. Stevenson JC. Justification for the use of HRT in the long term prevention of osteoporosis. Maturitas. 2005:51:113-26.

28. Lee $Y H$, Jin B, Lee S, Oh JY, Song J, Lee D, Kim YS, Kim H. A herbal formula HT051, a combination of Pueraria lobata and Rehmannia glutinosa, prevents postmenopausal obesity in ovariectomized rats. Evid Based Complement Alternat Med. 2017.

29. Tanidir Y, Ercan F, Tarcan T. Exogenous testosterone and estrogen affect bladder tissue contractility and histomorphology differently in rat ovariectomy model. J Sex Med. 2011;8(6):1626-37.

30. Choudhary YK, Bommu P, Ming YK, Zulkawi NB. Acute, sub-acute, and subchronic 90-days toxicity of Eurycoma longifolia aqueous extract (Physta) in wistar rats. Int J Pharm Pharm Sci. 2012;4(3).

31. Department of Standards Malaysia. Phytochemical aspect of freeze dried water extract from Tongkat Ali roots- specification. (Malaysian standard MS 2409:2011/ICS:67.040). Shah Alam: Department of Standards Malaysia, Ministry of Science, Technology and Innovation, Cyberjaya, Malaysia/ Standards \& Industrial Research Institute of Malaysia (SIRM); 2011.

32. The University of British Columbia. Rodent anaesthesia and analgesic formulary and general drug information. Canada: The University of British Columbia, Animal care committee SOP/Guidelines; 2016.

33. Behr GA, Schnorr CE, Moreira JC. Increased blood oxidative stress in experimental menopause rat model: the effects of vitamin a low-dose supplementation upon antioxidant status in bilateral ovariectomised rats. Fundam Clin Pharmacol. 2012;26(2):235-49.

34. Kim D, Choi MS, Pak SC, Lee SB, Jeon S. The effects of Sutaehwan-Gami on menopausal symptoms induced by ovariectomy in rats. BMC Complement Altern Med. 2012;12:227.

35. Xue L, Wang Y, Jiang Y, Han T, Nie Y, Zhao L, Qin L. Comparative effects of er-xian decoction, epimedium herbs, and icariin with estrogen on bone and reproductive tissue in ovariectomised rats. Evid Based Complement Alternat Med. 2012;2012:241416.

36. Bongartz TA, Scholmerich J, Straub RH. In: Maricic M, Gluck OS, editors. From osteoporosis in postmenopausal women. In Bone disease in rheumatology. Arizona: Lippincott Williams and Wilkens; 2005. p. 155-6.

37. Elkomy MM, Elsaid FG. Anti-osteoporotic effect of medical herbs and calcium supplementation on ovariectomized rats. J Basic Appl Zool. 2015;72:81-8.

38. Shiraishi A, Takeda S, Masaki T, Higuchi Y, Uchiyama Y, Kubodera N, Ogata E. Alfacalcidol inhibits bone resorption and stimulates formation in an ovariectomized rat model of osteoporosis: distinct actions from estrogen. $J$ Bone Miner Res. 2000:15(4):770-9.

39. Bhattarai T, Bhattacharya K, Chaudhuri P, Sengupta P. Correlation of common biochemical markers for bone turnover, serum calcium, and alkaline phosphatase in post-menopausal women. MJMS. 2014;21(1):58.

40. Jayusman PA, Mohamed IN, Alias E, Dom SM, Shuid AN. Effects of standardized quassinoid-rich Eurycoma longifolia extract in a rat model of osteoporosis due to testosterone deficiency: A densitometric, morphometric and biomechanical study. J Xray Sci Technol. 2018; (Preprint):1-14

41. Xie F, Wu CF, Lai WP, Yang XJ, Cheung PY, Yao XS, Leung PC, Wong MS. The osteoprotective effect of Herbaepimedii (HEP) extract in vivo and in vitro. Evid Based Complement Alternat Med. 2005;2:353-61.

42. Brokaw JJ, Tunnicliff G, Raess BU, Saxon DW. The teaching of complementary and alternative medicine in U.S. medical schools: a survey of course directors. Acad Med. 2002;77(9):876-81.

43. Kargozar R, Azizi $H$, Salari R. A review of effective herbal medicines in controlling menopausal symptoms. Electron Physician. 2017;9(11):5826-33.
44. Low BS, Das PK, Chan KL. Standardized quassinoid-rich Eurycoma longifolia extract improved spermatogenesis and fertility in male rats via the hypothalamic-pituitary-gonadal axis. J Ethnopharmacol. 2013;145(3):706-14.

45. Ali JM, Saad JM. Biochemical effect of Eurycoma longifolia jack on the sexual behavior, fertility, sex hormone, and glycolysis. Department of Biochemistry, University of Malaysia: PhD Dissertation; 1993.

46. George A, Henkel R. Phytoandrogenic properties of Eurycoma longifolia as natural alternative to testosterone replacement therapy. Andrologia. 2014; 46(7):708-21.

\section{Publisher's Note}

Springer Nature remains neutral with regard to jurisdictional claims in published maps and institutional affiliations.
Ready to submit your research? Choose BMC and benefit from:

- fast, convenient online submission

- thorough peer review by experienced researchers in your field

- rapid publication on acceptance

- support for research data, including large and complex data types

- gold Open Access which fosters wider collaboration and increased citations

- maximum visibility for your research: over $100 \mathrm{M}$ website views per year

At $\mathrm{BMC}$, research is always in progress.

Learn more biomedcentral.com/submissions 